\title{
Solar-forced diurnal regulation of cave drip rates via phreatophyte evapotranspiration
}

\author{
Katie Coleborn $^{1,4}$, Gabriel C. Rau ${ }^{1,2}$, Mark O. Cuthbert ${ }^{3}$, Andy Baker ${ }^{1,4}$, and Owen Navarre ${ }^{4}$ \\ ${ }^{1}$ Connected Waters Initiative Research Centre, UNSW Australia, Kensington NSW 2052, Australia \\ ${ }^{2}$ Water Research Laboratory, School of Civil and Environmental Engineering, Manly Vale NSW 2093, Australia \\ ${ }^{3}$ School of Geography, Earth and Environmental Sciences, University of Birmingham, Birmingham, B15 2TT, UK \\ ${ }^{4}$ School of Biological, Earth and Environmental Sciences, UNSW Australia, Kensington NSW 2052, Australia
}

Correspondence to: Katie Coleborn (k.coleborn@unsw.edu.au)

Received: 9 January 2016 - Published in Hydrol. Earth Syst. Sci. Discuss.: 15 February 2016

Revised: 4 October 2016 - Accepted: 11 October 2016 - Published: 3 November 2016

\begin{abstract}
We present results of a detailed study of drip rate variations at 12 drip discharge sites in Glory Hole Cave, New South Wales, Australia. Our novel time series analysis, using the wavelet synchrosqueezed transform, reveals pronounced oscillations at daily and sub-daily frequencies occurring in 8 out of the 12 monitored sites. These oscillations were not spatially or temporally homogenous, with different drip sites exhibiting such behaviour at different times of year in different parts of the cave. We test several hypotheses for the cause of the oscillations, including variations in pressure gradients between karst and cave due to cave breathing effects or atmospheric and earth tides, variations in hydraulic conductivity due to changes in viscosity of water with daily temperature oscillations, and solar-driven daily cycles of vegetative (phreatophytic) transpiration. We conclude that the only hypothesis consistent with the data and hydrologic theory is that daily oscillations are caused by solar-driven pumping by phreatophytic trees which are abundant at the site. The daily oscillations are not continuous and occur sporadically in short bursts (2-14 days) throughout the year due to nonlinear modification of the solar signal via complex karst architecture. This is the first indirect observation leading to the hypothesis of tree water use in cave drip water. It has important implications for karst hydrology in regards to developing a new protocol to determine the relative importance of trends in drip rate, such as diurnal oscillations, and how these trends change over timescales of weeks to years. This information can also be used to infer karst architecture. This study demonstrates the importance of vegetation on recharge dynamics, information that will inform both process-based
\end{abstract}

karst models and empirical estimation approaches. Our findings support a growing body of research exploring the impact of trees on speleothem paleoclimate proxies.

\section{Introduction}

Karst architecture determines the flow and storage of water from the surface to the underlying cave and is a major influence on drip discharge. Karst systems are characterised by three principle flow types. Primary flow occurs where the water travels through the primary porosity of the rock matrix, secondary flow pathways are characterised by water transported along fractures in the bedrock and tertiary flow pathways consist of conduits enlarged by dissolution. The dominance of a particular flow regime changes over time; for example, older limestone tends to have higher secondary porosity (more fractures and enlarged conduits) and a lower primary porosity due to compaction or cementation (Ford and Williams, 1994). The relationship between karst architecture and delivery of water to cave drip discharge sites has been studied to constrain uncertainty in paleoclimate studies (Bradley et al., 2010; Markowska et al., 2015), identify suitable speleothems as climate archives (McDonald and Drysdale, 2007) and, in conjunction with drip water geochemistry, determine water residence times in karst aquifers (Arbel et al., 2010; Fairchild et al., 2000; Lange et al., 2010; Sheffer et al., 2011; Tooth and Fairchild, 2003; Bradley et al., 2013). Recent research examining drip hydrology and fluctuations in drip rate have used hydrological response to characterise 
flow paths. For example, Markowska et al. (2015) used statistical analysis of drip hydrology data to identify storage flow, in both the epikarst and overlying soil, to develop conceptual models of a karst system.

Over a timescale of months to years, fluctuations in drip discharge are typically driven by seasonal variation in water availability (Hu et al., 2008; Sondag et al., 2003) and long-term climate forcings such as the North Atlantic Oscillation or El Niño-Southern Oscillation (McDonald, 2004; Proctor et al., 2000). On a daily to weekly timescale, drip rate responds to individual rainfall events (Baldini et al., 2012) and barometric changes (Genty and Deflandre, 1998; Jex et al., 2012; Tremaine and Froelich, 2013). Tremaine and Froelich (2013) found weekly and daily fluctuations at one drip site where an increase in barometric pressure decreased volumetric drip rate. This was attributed to atmospheric tides, the heating and cooling of the atmosphere, as the diurnal cycles occurred at $2 \mathrm{~h}$ before the solar noon (S1) and solar midnight (S2) each day. The cave was situated in poorly to moderately indurated Oligocene limestone with a high likelihood of primary porosity (Scott, 2001). Jex et al. (2012) observed a negative correlation between weekly barometric pressure changes and drip rate at 2 out of 40 drip sites monitored at the base of a paleokarst feature in the marmorised and fractured Devonian limestone at Cathedral Cave, NSW. One drip discharge site had a relatively strong anti-correlation $(R=-0.52)$ after accounting for a $40 \mathrm{~h}$ time lag. This relationship was attributed to a two-phase flow, where pressure fluctuations expanded and compressed air bubbles in the water held within the paleokarst in the unsaturated zone.

Non-linear and chaotic behaviour of drip discharge has been observed over very short (second to minutes) timescales. Chaotic drip regimes were first noted by Genty and Deflandre (1998) in the Devonian limestone of southern Belgium (Genty and Deflandre, 1998). Chaotic and nonlinear drip responses were also observed at an event scale in the fractured-rock limestone of Cathedral Cave, NSW (Mariethoz et al., 2012). These were attributed to the filling and draining of subsurface karst stores within a recharge event, with increasing homogenisation of flow with the filling of the stores. Baker and Brunsdon (2003) observed non-linear responses to rainfall in multi-year drip time series from a fractured rock (Carboniferous limestone) in Yorkshire, UK. With the exception of Tremaine and Froeclich (2013), daily fluctuations have not been observed in cave drip water hydrology.

In this paper we aim to increase our understanding of karst architecture by using a novel approach, the wavelet synchrosqueezed transform, to analyse drip discharge time series from 12 drip discharge sites in Glory Hole Cave, SE Australia. This analysis allows us to characterise daily and subdaily fluctuations in drip rate and identify the processes driving these oscillations. This study has important implications for understanding karst unsaturated flow processes and karstic groundwater recharge. Currently, most karst mod- els use very simplistic representations of unsaturated flow, if it is considered at all (Hartmann et al., 2014a). This study highlights the importance of vegetation dynamics on vadose flow and recharge, making it significant to karst modelling research and speleothem-based paleoclimate studies which focus on the impact of vegetation dynamics on proxy records (Treble et al., 2015, 2016a).

\section{Field site and methods}

\subsection{Glory Hole Cave at Yarrangobilly Caves National Park}

Glory Hole Cave is part of the Yarrangobilly Caves National Park located in the Snowy Mountains, New South Wales, Australia $\left(35^{\circ} 43^{\prime} 29.3^{\prime \prime} \mathrm{S}, 148^{\circ} 29^{\prime} 14.9^{\prime \prime} \mathrm{E}\right)$, at an elevation of $980 \mathrm{~m}$ (Australian Height Datum). The Snowy Mountains forms part of the Great Dividing Range, a mountainous region stretching along the eastern seaboard from Queensland to Victoria. The region is sub-alpine and the climate is classified as temperate montane with mild summers and no dry season (Köppen climate classification Cfb) (Peel et al., 2007; Stern et al., 2012).

Glory Hole Cave is formed of two main sections connected by a narrow constriction $\sim 2 \mathrm{~m} \times 6 \mathrm{~m}$. It is $\sim 243 \mathrm{~m}$ in length and is $\sim 100 \mathrm{~m}$ at its widest point. The cave extends more than $40 \mathrm{~m}$ below the surface in an unsaturated zone of westward sloping limestone bedrock with a contributing catchment area of $\sim 1 \mathrm{~km}^{2}$. The cave is situated within a formation of massive limestone approximately $12 \mathrm{~km}$ long and on average $1 \mathrm{~km}$ wide (Worboys, 1982). The limestone is typical of south-eastern Australian limestone; it is Silurian, highly fractured and marbleised with little primary porosity. The bedding planes of the limestone are generally obvious with a westward dip (Adamson and Loudon, 1966). It is likely that Glory Hole Cave was formed by water running off less permeable rocks to the east of the limestone, sinking to the water table and rising through large springs close to the Yarrangobilly River (Spate, 2002), which is situated in a gorge in $<100 \mathrm{~m}$ west of the cave entrance. Glory Hole Cave is likely to be relevant for paleoclimate proxies as there is an abundance of speleothems and in close proximity $(<100 \mathrm{~m})$ to caves that have been used in multi-proxy speleothem-based paleoclimate studies (Markowska et al., 2015; Webb et al., 2014).

The vegetation is classified as sub-alpine open snow gum (Eucalyptus pauciflora subsp. pauciflora) and black sallee (E. stelullata) woodland.

\subsection{Cave and surface monitoring}

Drip discharge rate was recorded at 12 drip sites in three locations (Fig. 1 and Table 1) within Glory Hole Cave using Stalagmate ${ }^{\odot}$ drip loggers between December 2012 and September 2015, and monitoring is ongoing. The drip sites 

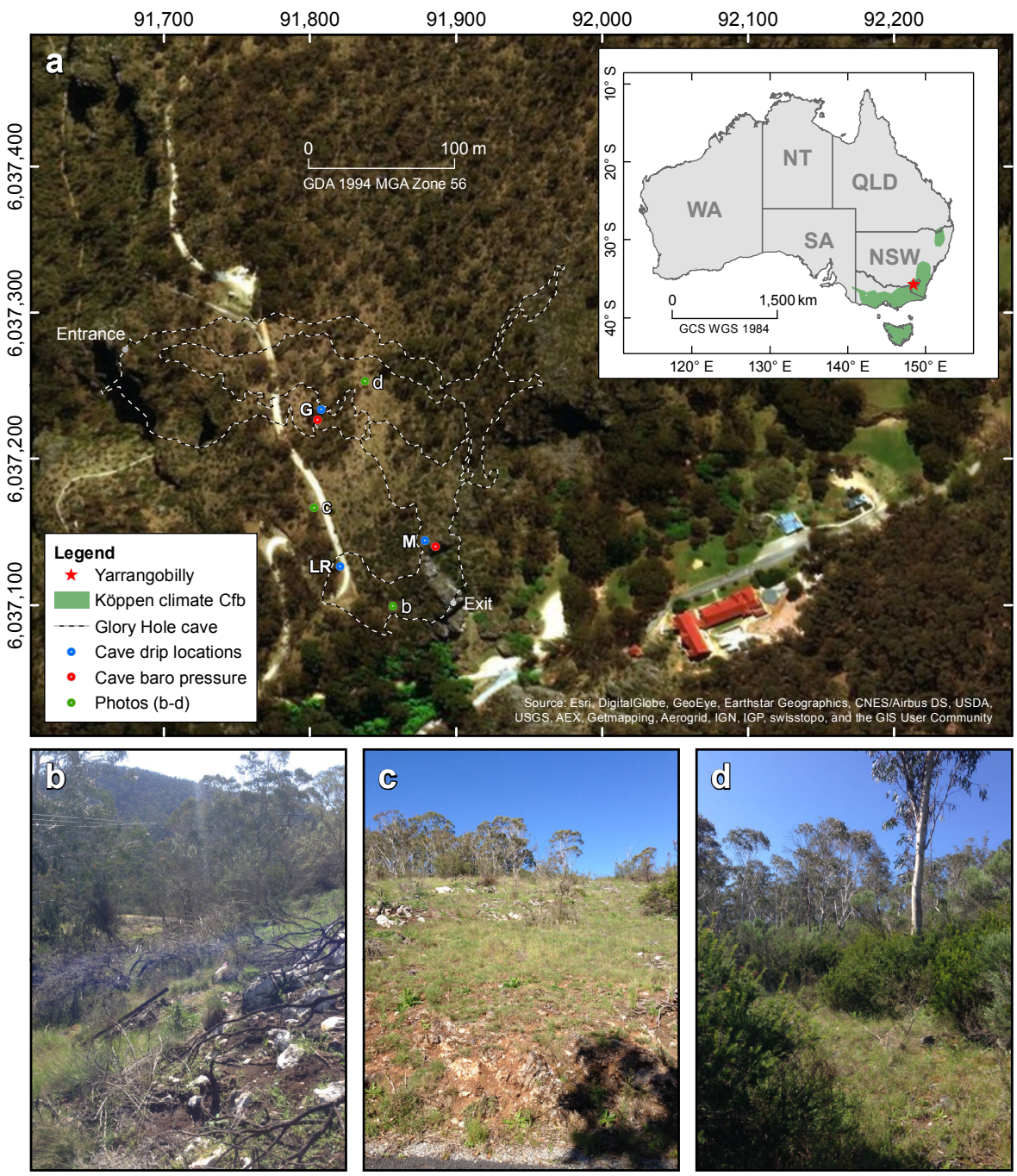

Figure 1. Location of Yarrangobilly Caves in New South Wales, Australia, with photos of surface vegetation (b-d). Extent of Köppen climate zone is from Peel et al. (2007).

were chosen using a stratified sampling method. A transect of the cave was used to select three locations $(\mathrm{G}, \mathrm{M}$ and LR) that satisfied the following criteria: (1) there were actively dripping speleothems, (2) spatially distant from the other locations and (3) different depths within the cave. Individual drips were sampled randomly at each location, with selection guided by practical constraints such as stalagmite surface being suitable for placement of logger and the drip falling from high enough to activate pressure sensor on the logger. Drip loggers recorded the frequency of drips falling onto the surface of the sealed box containing an acoustic sensor in $15 \mathrm{~min}$ intervals. The number of drips were converted to $\mathrm{mL} \mathrm{min}^{-1}$, assuming that 1 drip equals $0.19 \mathrm{~mL}$ (Collister and Mattey, 2008; Markowska et al., 2015). Recently, automated drip loggers have been widely used in cave hydrology research (Cuthbert et al., 2014b; Hu et al., 2008; Mahmud et al., 2016; Rutlidge et al., 2014; Treble et al., 2016b) as they provide a more convenient and efficient way of recording higher temporal resolution data than traditional drip counting methods.

Barometric pressure and air temperature were recorded at two locations within the cave (Fig. 1) using Solinst level loggers at 15 min intervals from January to September 2015. Precipitation (accuracy $\pm 4 \%$ of total $\mathrm{mm}$ ), wind speed (accuracy $\pm 0.1 \mathrm{kph}$ ), relative humidity (accuracy $\pm 2 \%$ ), air temperature (accuracy $\pm 0.5^{\circ} \mathrm{C}$ ) and barometric pressure (accuracy: $\pm 1.0 \mathrm{kPa}$ ) were measured with a Davis Vantage Pro 2 weather station $<1 \mathrm{~km}$ from Glory Hole Cave at $15 \mathrm{~min}$ intervals and data stored using a Datataker DT80 data logger. Solar radiation $\left(\mathrm{W} \mathrm{m}^{-2}\right)$ was derived from satellite imagery processed by the Bureau of Meteorology from the Geostationary Meteorological Satellite and MTSAT series. 
Table 1. Summary of drip sites and location within cave as indicated in Fig. 1, the monthly mean and standard deviation (std) of total flow volume and maximum and minimum drip rate in summer (December-February) and winter (June-August).

\begin{tabular}{|c|c|c|c|c|c|c|c|c|c|}
\hline \multirow[b]{3}{*}{ Site } & \multirow[b]{3}{*}{ Location } & \multicolumn{4}{|c|}{ Total flow volume (L) } & \multicolumn{4}{|c|}{ Drip rate $\left(\mathrm{mL} \mathrm{min}^{-1}\right)$} \\
\hline & & \multicolumn{2}{|c|}{ Summer } & \multicolumn{2}{|c|}{ Winter } & \multicolumn{2}{|c|}{ Summer } & \multicolumn{2}{|c|}{ Winter } \\
\hline & & Mean & SD & Mean & SD & Maximum & Minimum & Maximum & Minimum \\
\hline G1 & \multirow{6}{*}{ G } & 72.67 & 9.21 & 209.58 & 107.78 & 19.51 & 1.84 & 56.75 & 0.00 \\
\hline G3 & & 23.76 & 10.13 & 115.44 & 8.37 & 7.00 & 0.00 & 34.43 & 0.00 \\
\hline G6 & & 3.73 & 1.90 & 16.45 & 0.10 & 1.43 & 0.10 & 4.10 & 0.65 \\
\hline G8 & & 6.36 & 0.49 & 5.81 & 0.16 & 1.11 & 0.00 & 0.96 & 0.34 \\
\hline G10 & & 32.47 & 23.08 & 104.54 & 73.58 & 9.97 & 0.04 & 27.27 & 0.00 \\
\hline G12 & & 6.57 & 5.71 & 9.74 & 4.39 & 1.68 & 0.00 & 2.04 & 0.43 \\
\hline LR1 & LR & 32.31 & 23.93 & 98.62 & 7.39 & 58.30 & 0.00 & 57.77 & 0.00 \\
\hline M1 & \multirow{5}{*}{ M } & 0.29 & 0.18 & 0.47 & 0.00 & 0.13 & 0.00 & 0.11 & 0.00 \\
\hline M2 & & 7.67 & 12.85 & 120.09 & 21.21 & 42.53 & 0.00 & 74.30 & 0.00 \\
\hline M4 & & 0.88 & 1.47 & 33.95 & 5.17 & 4.02 & 0.00 & 28.45 & 0.00 \\
\hline M10 & & 24.53 & 34.68 & 127.79 & 51.36 & 13.95 & 0.00 & 27.56 & 0.00 \\
\hline M13 & & 7.33 & 5.05 & 67.03 & 6.60 & 12.40 & 0.09 & 41.80 & 0.92 \\
\hline
\end{tabular}

Daily potential evapotranspiration was estimated using "ETo Calculator" software developed by the Land and Water Division of the Food and Agriculture Organisation of the United Nations (http://www.fao.org/nr/water/eto.html). The software is based on the Penman-Monteith equation and is a physically based method with physiological and aerodynamic parameters. The climate parameters used were air temperature (mean, maximum and minimum), relative humidity (mean, maximum and minimum), wind speed and solar radiation.

\subsection{Spectral analysis of cave drip discharge rates}

A new advance in signal processing was used to analyse the time-frequency content of measured cave drip discharge rate, temperature and barometric pressure. Here, the frequencies of interest are 1 cycle per day (cpd) and faster, i.e. diurnal to sub-diurnal. Daubechies et al. (2011) first presented the wavelet synchrosqueezed transform (WSST) as an empirical mode decomposition like tool for disentangling an amplitude and phase modulated signal into approximately harmonic components. Thakur et al. (2013) adapted the WSST to discretised data (rather than continuous functions) and developed a MATLAB ${ }^{\circledR}$ Synchrosqueezing Toolbox (available for download: https://web.math.princeton.edu/ ebrevdo/synsq/) which efficiently implements the WSST algorithm and offers a $\log$ base 2 frequency resolution (WSST was officially implemented in MATLAB ${ }^{\circledR}$ as of release R2016a). They further tested the robustness properties of WSST and found that it precisely estimated key signal components and that it was stable against errors and noise (Thakur et al., 2013). The WSST combines advantages of the wavelet transform in regards to frequency resolution with the frequency reallocation method (Auger and Flandrin, 1995) in order to reduce spectral smearing when mapping out the time-frequency content of a complicated signal.

The drip discharge rate time series, barometric pressure and air temperature (potential weather-related drivers of drip discharge oscillations) were analysed for time-frequency content in the following way:

- The WSST functions in MATLAB ${ }^{\circledR}$ (version R2016a or later) or the Synchrosqueezing Toolbox (Thakur et al., 2013) are applied to compute the signal's frequency content over time. The output is a 2-D matrix containing the complex frequency domain response $F_{f, t}$ with elements corresponding to discrete frequency and time values (e.g. as rows and columns). Here, $f$ is frequency (in $\log$ base 2 resolution) [1/T] and $t$ is discrete time (sampling resolution) [T].

- The component amplitudes according to the standard signal processing procedure are calculated using

$$
A_{f, t}=\left|F_{f, t}\right|=\sqrt{\mathcal{I}\left(F_{f, t}\right)^{2}+\mathcal{R}\left(F_{f, t}\right)^{2}} .
$$

- The component amplitudes are normalised using

$$
a_{f, t}=\frac{A_{f_{\min }<f<f_{\max }, t}}{\max \left(A_{f_{\min }<f<f_{\max }, t}\right)} .
$$

In order to highlight the main frequency components of interest ( 1 and $2 \mathrm{cpd}$ ) we chose $f_{\min }=0.5$ and $f_{\max }=4 \mathrm{cpd}$ for the normalisation. However, for other applications different frequency limits could be useful to identify continuous periods of weaker frequency components in the presence of other, stronger components as well as chaos. 
- The normalised amplitude matrices are visualised in pseudo-colour plots. Distinct frequency components (signals with contrasting amplitudes whose frequency does not significantly change over time) can easily be distinguished from chaos (i.e. lack of regular oscillations identified as signals with varying amplitude and frequency over time). Stronger periodic components would yield larger amplitudes and therefore also a value that is closer to 1 in the respective WSST plots. While this analysis is conducted manually, it could be automated using criteria for the strength, continuity and stability of any frequency component of interest.

An example of the time-frequency mapping conducted according to the above described method is illustrated in Fig. 2. The results obtained by applying the WSST (Fig. 2b) can be compared to the results from a continuous wavelet transform (CWT) with a Morlet mother wavelet (Fig. 2c) (Torrence and Compo, 1998). From this example it is clear that WSST features significantly less time-frequency smearing and therefore allows improved identification and delineation of close-by frequency components such as those at 1 or $2 \mathrm{cpd}$ (compare Fig. 2b and c). Therefore, WSST presents a significant advantage over traditional signal processing methods such as the continuous wavelet transform when identifying the timing and duration of multiple frequency components embedded in measurements.

Using this methodology, a periodic drip discharge rate could be defined as consisting of continuous periods of (a) stable $1 \mathrm{cpd}$ frequency, (b) stable 1 and $2 \mathrm{cpd}$ frequency and (c) chaos (components with randomly varying frequency and amplitude). We used (a) and (b) as spectral "fingerprints" to identify and mark periods of continuous occurrence of daily and sub-daily oscillations in the drip discharge rate dataset.

\section{Results}

\subsection{Drip discharge rate time series}

The drip discharge time series are presented in Fig. 3. The drip discharge sites are spatially clustered in three groups within the cave (Fig. 1 and Table 1). Sites with the G prefix are located near the main entrance of the cave on the western side. The location is highly decorated with speleothems. $\mathrm{M}$ sites are located in the middle section of the cave in a large chamber with a high ceiling populated by soda straw formations. Location LR1 is situated near the cave exit at the top of a flow stone.

The drip discharge rate at G1 and G3 varies seasonally, with higher drip rates in winter, total flow volume of 133.37 and $109.52 \mathrm{~L}$, respectively, than summer (64.56 and $14.1 \mathrm{~L}$, respectively). Drip rate increases in response to rainfall events during the wet season and gradually decreases through the drier part of the year. Drip rate is lowest during

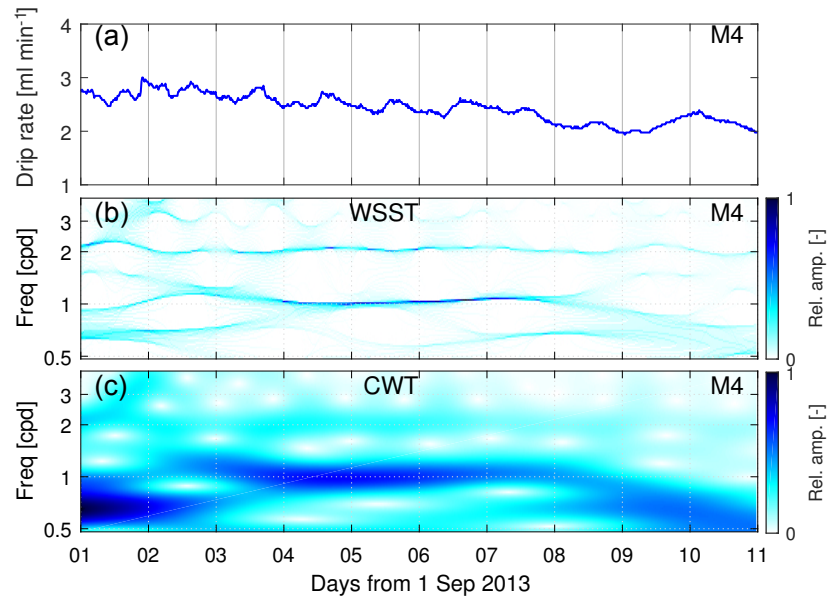

Figure 2. Comparing the time-frequency content of the drip discharge rate (a) for drip site M4 (refer to Fig. 3): relative component amplitudes calculated from (b) the wavelet synchrosqueezed transform (WSST) and (c) the continuous wavelet transform (CWT) using a Morlet mother wavelet.

April and May and highest during June and July. Similarly, G6 exhibits seasonal variation with a higher volume of discharge during the winter than summer. The drip rate at G10 increases sharply from $0.14 \mathrm{~mL} \mathrm{~min}^{-1}$ on 21 July 2013 to $13.75 \mathrm{~mL} \mathrm{~min}^{-1}$ on 29 July 2013 . This drip rate is consistently sustained for 3 months, indicated by the flat topped hydrograph (Fig. 3). From July 2013 onwards, the drip rate gradually decreases until June 2014 when it increases sharply again by an order of magnitude from $2.03 \mathrm{~mL} \mathrm{~min}^{-1}$ on 3 June 2014 to $24.96 \mathrm{~mL} \mathrm{~min}^{-1}$ on 4 July 2014. In May 2014, the drip rate again rapidly increases at G10 from 0.142 to $21.59 \mathrm{~mL} \mathrm{~min}^{-1}$ on 18 April 2014 and then proceeds to gradually decline until April 2015 when it reaches baseline conditions. M10 exhibits similar behaviour with a low baseline drip rate which increases sharply during July 2013 and is sustained for $\sim 3$ months; however, the elevated drip rate decreases more rapidly than G10, returning to baseline conditions in January 2014. M1 has a very low drip rate ranging from 0 to $0.13 \mathrm{~mL} \mathrm{~min}^{-1}$ and is seasonally variable with higher drip rates during the winter. LR1, M2, M4 and M13 are very responsive to infiltration events and are characterised by a "flashy" flow type, evidenced by the frequent spikes in drip rate. G12 has a low discharge rate which gradually decreases over the monitoring period until the site dries up completely in November 2014. There are small variations in drip rate that are not associated with rainfall events or seasonal drying. G8 is the only site which has a lower total flow volume during the winter $(2013=5.92 \mathrm{~L} ; 2014=5.7 \mathrm{~L})$ than summer $(2014=6.39 \mathrm{~L} ; 2015=6.84 \mathrm{~L})$. 

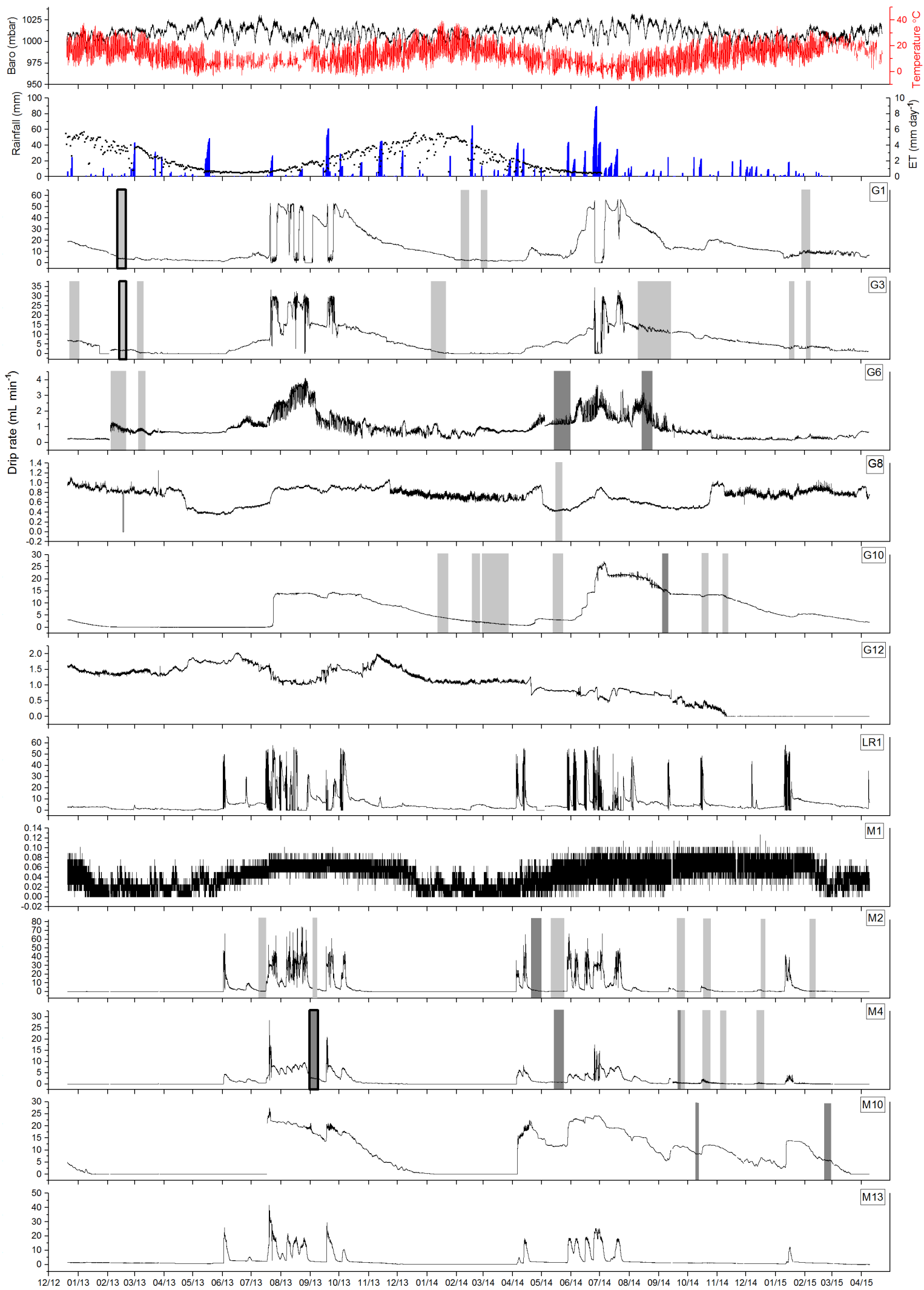

Figure 3. Drip discharge rate time series for all drip sites in Glory Hole Cave with periods where daily fluctuations occur highlighted in light grey ( $1 \mathrm{cpd})$ and dark grey ( 1 and $2 \mathrm{cpd})$. The time periods examined in more detail in Figs. 4-6 are indicated by bolder outline. Daily evapotranspiration (19 December 2012-3 July 2014), rainfall, barometric and air temperature are also shown. 

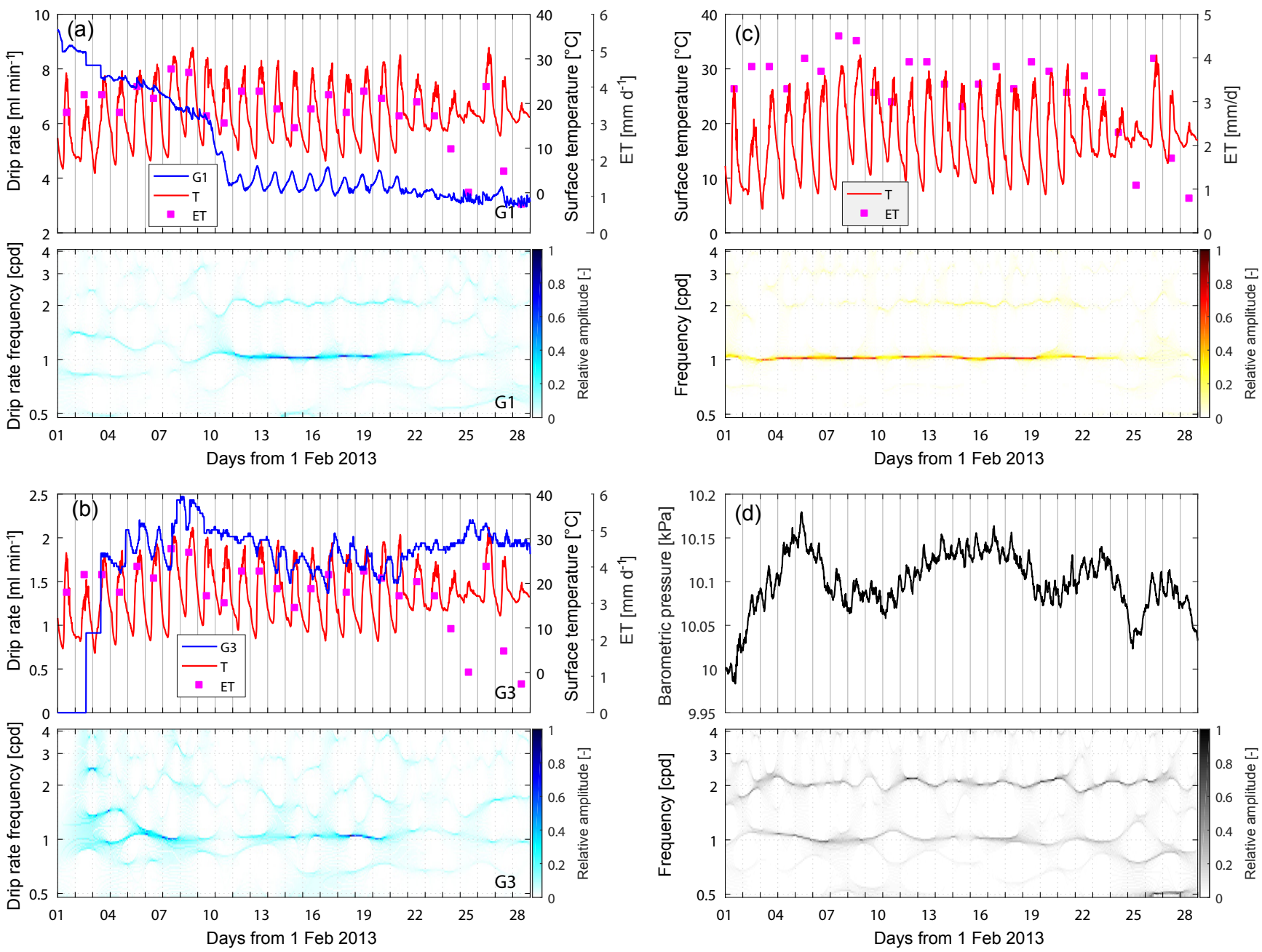

Figure 4. The raw drip rate, evapotranspiration and surface temperature data with the corresponding drip rate WSST plot for time periods where a 1 cpd signal is present for sites (a) G1 and (b) G3, (c) surface air temperature ( $T$ ) and potential evapotranspiration (ET) and (d) barometric pressure for period February 2013.

\subsection{Characterisation of oscillations in the drip discharge rate}

Daily fluctuations in drip discharge rate were identified in 8 out of 12 sites using WSST. There was no connection between the sites that did not exhibit the fluctuations with respect to spatial location, flow volume or flow regime type. The temporal and spatial pattern of daily oscillations are shown by the grey shaded areas in Fig. 3. The length of time the signal is present varied temporally for each drip site. For example, there was a strong $1 \mathrm{cpd}$ signal in the drip water at G1 for 10 days in February 2013 whereas in January 2014 $1 \mathrm{cpd}$ fluctuations only lasted 5 days (Fig. 4). The timing of when the signal occurs on an annual scale varied within and between drip sites. For example, a $1 \mathrm{cpd}$ signal only occurred during the first 3 months of the year for G1, whereas a $1 \mathrm{cpd}$ signal occurred sporadically at G3 throughout the cal- endar year (December 2012, February and March 2013, January 2014, September 2014, January 2015).

The daily timing of minimum and maximum drip rate varied within and between individual drip sites. At G1 the $1 \mathrm{cpd}$ maximum and minimum drip rate generally around 06:00 00:00 and 00:00-21:00 LT, respectively. Daily oscillations were only observed once at G8 between 14 and 21 May 2014 with minimum drip rate at 03:00-09:00 LT and maximum drip rate around 00:00-21:00 LT. Both 1 and $2 \mathrm{cpd}$ signals were observed at M10 for all the periods of drip rate oscillation with the larger peak occurring in the afternoon around 15:00-18:00 LT, minimum drip rate appeared consistently between 06:00 and 09:00 LT. Time lag between air temperature and drip rate was quantified by performing a cross correlation analysis with a shift interval of $15 \mathrm{~min}$ up to $\pm 24 \mathrm{~h}$ (Table 2). The lag time was identified as the point of maximum negative correlation between the two variables with the exclusion of sites with missing data. At most sites the lag 
Table 2. The time lag calculated using cross correlation analysis between air temperature and daily drip rate for each period of drip rate oscillation; the timing of when minimum and maximum drip rate occurred within the time periods * denote periods where a 2 cpd signal occurs. A negative time lag means the minimum drip rate lags behind the peak temperature whereas a positive lag means the minimum drip rate precedes the maximum temperature.

\begin{tabular}{|c|c|c|c|c|c|c|}
\hline \multirow[b]{2}{*}{ Site } & \multicolumn{2}{|c|}{ Drip rate oscillation period } & \multirow{2}{*}{$\begin{array}{l}\text { Time } \\
\text { lag }(\mathrm{h})\end{array}$} & \multirow{2}{*}{$\begin{array}{r}R^{2} \\
(p \text { value }<0.05)\end{array}$} & \multirow{2}{*}{$\begin{array}{c}\text { Max drip rate } \\
\text { From-to }\end{array}$} & \multirow{2}{*}{$\begin{array}{c}\text { Min drip rate } \\
\text { From-to }\end{array}$} \\
\hline & Start & End & & & & \\
\hline \multirow[t]{4}{*}{ G1 } & 11 Feb 2013 & 21 Feb 2013 & -11.5 & -0.82 & 09:00-12:00 & 18:00-21:00 \\
\hline & 4 Feb 2014 & 14 Feb 2014 & -12.75 & -0.55 & 09:00-12:00 & 18:00-21:00 \\
\hline & 27 Feb 2014 & 10 Mar 2014 & -11.25 & -0.37 & 09:00-12:00 & $12: 00-21: 00$ \\
\hline & 27 Jan 2015 & 5 Feb 2015 & -11.5 & -0.69 & 06:00-12:00 & $12: 00-21: 00$ \\
\hline \multirow[t]{7}{*}{ G3 } & 23 Dec 2012 & 2 Jan 2013 & -23.25 & -0.46 & 12:00-00:00 & 00:00-09:00 \\
\hline & 12 Feb 2013 & 20 Feb 2013 & 2 & -0.56 & 15:00-00:00 & $06: 00-15: 00$ \\
\hline & 4 Mar 2013 & 10 Mar 2013 & 1 & -0.44 & 15:00-00:00 & 03:00-09:00 \\
\hline & 6 Jan 2014 & 20 Jan 2014 & 7 & -0.62 & 00:00-09:00 & $12: 00-18: 00$ \\
\hline & 20 Sep 2014 & 29 Sep 2014 & -4 & -0.38 & 09:00-18:00 & 03:00-06:00 \\
\hline & 16 Jan 2015 & 20 Jan 2015 & 0.25 & -0.59 & 18:00-21:00 & 03:00-09:00 \\
\hline & 3 Feb 2015 & 6 Feb 2015 & 1 & -0.74 & 15:00-21:00 & 06:00-09:00 \\
\hline \multirow[t]{4}{*}{ G6 } & 3 Feb 2013 & 19 Feb 2013 & -4 & -0.19 & 18:00-00:00 & 03:00-06:00 \\
\hline & 5 Mar 2013 & 12 Mar 2013 & -3.25 & -0.51 & $15: 00-21: 00$ & 03:00-09:00 \\
\hline & 13 May 2014 & 29 May $2014^{*}$ & -21 & -0.5 & 15:00-18:00 & 03:00-06:00 \\
\hline & 14 Aug 2014 & 24 Aug 2014* & -7 & -0.5 & 15:00-18:00 & 21:00-00:00 \\
\hline G8 & 14 May 2014 & 21 May 2014 & -9.5 & -0.55 & $12: 00-21: 00$ & 03:00-09:00 \\
\hline \multirow[t]{8}{*}{ G10 } & 5 Oct 2013 & 16 Oct $2013^{*}$ & -24 & -0.4 & 15:00-18:00 & 03:00-06:00 \\
\hline & 5 Jan 2014 & 22 Jan 2014 & -0.5 & -0.32 & 15:00-21:00 & 03:00-06:00 \\
\hline & 18 Feb 2014 & 24 Feb 2014 & -3 & -0.46 & 15:00-21:00 & 21:00-00:00 \\
\hline & 4 Mar 2014 & 23 Mar 2014 & -2.75 & -0.47 & 15:00-18:00 & 03:00-09:00 \\
\hline & 13 May 2014 & 23 May 2014 & -15 & -0.37 & 15:00-00:00 & 00:00-06:00 \\
\hline & 16 Oct 2014 & 22 Oct $2014^{*}$ & -23 & -0.49 & 15:00-21:00 & 06:00-09:00 \\
\hline & 8 Nov 2014 & 12 Nov 2014 & -1.5 & -0.59 & 18:00-21:00 & 06:00-09:00 \\
\hline & 5 Feb 2015 & 25 Feb 2015 & -0.25 & -0.33 & 15:00-21:00 & 06:00-09:00 \\
\hline \multirow[t]{6}{*}{ M2 } & 3 Sep 2013 & 7 Sep 2013 & -15.25 & -0.76 & 15:00-18:00 & 06:00-09:00 \\
\hline & 20 Apr 2014 & 28 Apr 2014* & -1 & -0.4 & 00:00-03:00 & 06:00-09:00 \\
\hline & 13 May 2014 & 21 May 2014 & -17.75 & -0.6 & 15:00-18:00 & 06:00-09:00 \\
\hline & 20 Sep 2014 & 28 Sep 2014 & -23.75 & -0.4 & 15:00-18:00 & 06:00-09:00 \\
\hline & 18 Oct 2014 & 25 Oct 2014 & -2 & -0.31 & 15:00-18:00 & 06:00-09:00 \\
\hline & 5 Feb 2015 & 10 Feb 2015 & -20.75 & -0.51 & 00:00-03:00 & $12: 00-15: 00$ \\
\hline \multirow[t]{5}{*}{ M4 } & 2 Sep 2013 & 8 Sep 2013* & -24 & -0.46 & 12:00-18:00 & 06:00-09:00 \\
\hline & 14 May 2014 & 23 May $2014^{*}$ & -9 & -0.38 & 15:00-18:00 & 06:00-09:00 \\
\hline & 16 Oct 2014 & 24 Oct 2014 & -16.25 & -0.65 & 00:00-12:00 & $12: 00-21: 00$ \\
\hline & 4 Nov 2014 & 13 Nov 2014 & -16.5 & -0.62 & $21: 00-03: 00$ & $12: 00-21: 00$ \\
\hline & 12 Dec 2014 & 22 Dec 2014 & -16.5 & -0.32 & 00:00-09:00 & $18: 00-21: 00$ \\
\hline \multirow[t]{2}{*}{ M10 } & 23 Dec 2012 & 26 Dec $2012^{*}$ & -24 & -0.32 & 15:00-18:00 & 09:00-12:00 \\
\hline & 9 Oct 2014 & 12 Oct 2014 & -4.75 & -0.46 & 15:00-18:00 & 09:00-12:00 \\
\hline
\end{tabular}

time between maximum air temperature and minimum drip rate varied greatly over the monitoring period. For example, at M4 initially the lag time was $24 \mathrm{~h}$ in September 2013, decreasing to $9 \mathrm{~h}$ in May 2014 and eventually levelling off at around $16 \mathrm{~h}$ from September to December 2014. In contrast, G1 had a similar lag time over all four periods of drip rate fluctuation ranging from 11.25 to $12.75 \mathrm{~h}$. G6 was unique in that the minimum drip rate occurred before the maximum air temperature in February and March 2013, January 2014 and January 2015. Analysis of variance indicated that drip site and season did not explain a significant amount of variance in lag time.

1 and 2 cpd signals can occur concurrently, for example, at M4 between 1 and 9 September 2013 (Fig. 5). This trend, 
in which the $2 \mathrm{cpd}$ is weaker than the $1 \mathrm{cpd}$, is consistent across all sites where the two signals coincide. The $2 \mathrm{cpd}$ signal can be visually determined in the raw drip rate data by a second smaller peak. Examples of characteristic WSST plots alongside the corresponding raw drip rate and surface temperature data will be discussed in greater detail below. All WSST analyses have been plotted in the Supplement.

WSST identified a $1 \mathrm{cpd}$ oscillation in drip rate between 8 and 21 February 2013 at G1 and G3 (Fig. 4a and b). At G1 (Fig. 4a), the signal was initially chaotic, but from 8 to 21 February 2013 the drip rate oscillates sharply at $1 \mathrm{cpd}$. The maximum drip rate ranging from 4.03 to $3.75 \mathrm{~mL} \mathrm{~min}^{-1}$ occurred between 09:18 and 10:27 LT and the minimum drip rate ranging from 3.34 to $3.75 \mathrm{~mL} \mathrm{~min}^{-1}$ occurred between 18:39 and 21:27 LT. The signal was chaotic from 21 February 2013.

The drip rate at G3 (Fig. 4b) oscillated at $1 \mathrm{cpd}$ for 8 days from 12 to 20 February 2013. In contrast to G1, the maximum drip rate appeared in the evening and the minimum drip rate occurred in the morning. The maximum drip rate ranging from 1.63 to $2.01 \mathrm{~mL} \mathrm{~min}^{-1}$ occurred between 20:21 and 00:40 LT and the minimum drip rate ranging from 0.36 to $0.48 \mathrm{~mL} \mathrm{~min}^{-1}$ occurred between 09:03 and 11:36 LT with the exception of 15 and 18 February 2013, when it appeared at 14:06 and 12:57 LT, respectively. Similar to G1, the $1 \mathrm{cpd}$ trend descended into chaos from 20 February 2013 onwards. The maximum drip rate occurs between 14:23 and 22:45 LT and ranged from 0.53 to $1.14 \mathrm{~mL} \mathrm{~min}^{-1}$. The minimum drip rate occurred between 01:18 and 11:32 LT and ranged from 0.228 to $0.95 \mathrm{~mL} \mathrm{~min}^{-1}$.

From 1 to 27 February 2013, daily barometric pressure peaked between 08:30 and 09:00 LT with a magnitude of 0.1 to $0.5 \mathrm{kPa}$ with a smaller second peak between 20:00 and 22:00 LT with a magnitude of $0.1-0.3 \mathrm{kPa}$ (Fig. $4 \mathrm{c}$ ). There were larger changes in air pressure on a mesoscale with peaks in air pressure on 16, 22, 26 February 2013 and minimum air pressure on 19, 24 and 28 February 2013. The air pressure changes in these cycles were as much as $1.5-2 \mathrm{kPa}$. The drip rate at G1 and G3 did not appear to be affected by the daily or weekly changes in air pressure. For example, when air pressure decreased dramatically on 27 February 2013 (Fig. 4c) there was no substantial change in drip rate at either G1 or G3.

Insolation drives daily cycles in surface air temperature with maximum temperatures recorded between 11:30 and 16:00 LT and minimum temperatures recorded between 04:00 and 08:00 LT (Fig. 4d). The difference in daily minimum and maximum air temperature varied greatly. For example, between 12 and 20 February 2013 the difference was 17.05-22. $2^{\circ} \mathrm{C}$ whereas between 21 and 27 February 2013, the temperature difference was as little as $4.5^{\circ} \mathrm{C}$. Evapotranspiration ranged from 0.8 to $4.5 \mathrm{~mm} \mathrm{day}^{-1}$ and was relatively high from 1 to 23 February 2013 with a slight downward trend which then decreased sharply on 23 and 24 February 2013 to 2.3 and $1.1 \mathrm{~mm}^{-1}$ day $^{-1}$, respectively.

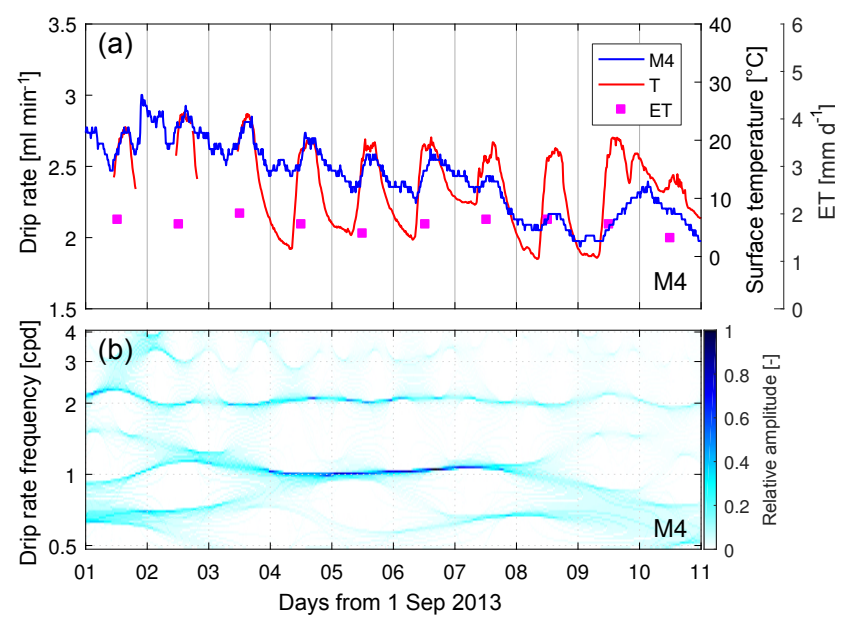

Figure 5. The raw drip discharge data, evapotranspiration, surface temperature and wavelet synchrosqueezed transform (WSST) plot of the drip discharge for site M4 from 1 to 11 September 2013.

\section{Discussion}

\subsection{Cave drip rate and karst architecture}

The complexity of the Glory Hole Cave karst system is evident in the variety of drip regimes. For example, the drip rate at G1, G6 and G3 is seasonally driven with high discharge rates during the wettest period of the year. In contrast, drip discharge at G10 and M10 is likely driven by a storage component which discharges via a less permeable pathway which limits the store at a particular level during wet periods. The drip site is fed via the main water store rather than the overflow pathway itself (Baker et al., 2012; Bradley et al., 2010). Sites LR1, M4, M13 and M2 behave similarly in that they are all very responsive to rainfall events and have low base flows during periods of low rainfall. The response to rainfall events occur within $24 \mathrm{~h}$ across these sites. Calculated flow volumes indicate the storage capacity of the stores feeding the discharge sites. For example, there was an infiltration event on 1 June 2013 which caused a dramatic increase in drip rate for sites LR1, M2, M4 and M13. The flow volumes for each site from the start of the event to the point where the discharge returns to a constant rate are as follows: LR1 $(1.60 \mathrm{~L})$, M4 (2.99L), M13 (8.09L) and M2 (11.30L). The length of the recession limb, calculated from the peak of the hydrograph until the drip rate returns to base rate, is indicative of the speed at which the store drains. For example, the decay in drip rate is 12 days for site M2 compared to 4 days for M13. The time it takes for the store to drain is not dependent on flow volume, as M13 has a flow volume of more than 5 times that of site LR1, but they both have drainage periods of 5 days. The discrepancy in drainage time could indicate variation in flow pathway length between sites. G8 is the only site with a relatively lower total flow volume during winter than summer. M1 has a low drip rate that shows a small seasonal 
fluctuation but does not visibly respond to individual events. This site is likely being fed by a store that is large enough to assimilate short-term inputs from the surface without impacting drip rate. This type of store has been described as a karst hydrological model component in a number of studies (Arbel et al., 2010; Hartmann et al., 2014b; Markowska et al., 2015).

\subsection{Daily oscillations in drip rate}

Constant frequency oscillations in drip discharge (1 and $2 \mathrm{cpd}$ ) occur sporadically throughout the monitoring period December 2012-April 2015 at 8 out of 12 monitored drip sites. This phenomenon could be explained by a number of daily drivers including variations in pressure gradients between karst and cave due to cave ventilation effects, atmospheric and earth tides or variations in hydraulic conductivity (due to changes in viscosity of water with daily temperature oscillations), and solar-driven daily cycles of vegetative (phreatophytic) transpiration. These drivers are now considered in turn.

\subsubsection{Cave ventilation effects}

Surface air pressure and cave air pressure were significantly correlated ( $\tau=0.82$ significant at $95 \%, n=8939)$ for the monitoring period 19 January-8 September 2015. This indicates that cave air exchange ("breathing" or ventilation) is very efficient and consequently that variations in air pressure between the cave and surface can be ruled out as driving the fluctuations in drip rate.

\subsubsection{Barometric loading}

Atmospheric tides are caused by changes in air pressure due to the heating and cooling of air masses during the day and night. Correlations between atmospheric tides and drip rates can occur since increases (decreases) in atmospheric pressure at the ground surface are partitioned into stress increase (decrease) in the soil/rock mass and pore pressure increase (decrease) within the formation (Acworth et al., 2015). Drip rates could be affected if this changes the pressure gradient between the groundwater in karst stores and the cave (Tremaine and Froelich, 2013). Such a pressure imbalance is dependent on the hydromechanical properties and karst architecture as well as the degree of pneumatic connection between both the surface and the water table, and the surface and the cave at the location of the drip. Maximum and minimum atmospheric pressure occur at the same time each day (Fig. 4d).

Atmospheric tides were eliminated as a process to explain the daily oscillation phenomenon for several reasons. Firstly, there was no relationship between drip discharge rate and the longer-term barometric changes caused by synoptic weather patterns (Fig. 4). The mesoscale fluctuations in pressure caused by synoptic weather patterns are an order of magnitude higher than those caused by daily atmospheric tides. Since the drip rate did not respond to pressure changes of this size, they will not respond significantly to changes of a smaller magnitude at a higher frequency because higher frequency signals will be more highly damped and lagged. Secondly, the timing of the daily maximum and minimum drip rates in Glory Hole Cave varied within each drip site over time. For example, the peak discharge time for site G6 varied between 13:24 and 19:48 LT for the period $11 \mathrm{Au}-$ gust 2013-25 August 2015. This finding contrasts with previous studies where drip rate is negatively correlated with barometric pressure and responds to daily pressure changes linearly (Tremaine and Froelich, 2013). However, this could indicate that the daily drip water variations in Glory Hole Cave are being driven by a non-linear process and this is discussed further below. Thirdly, the karst architecture of Glory Hole Cave is well-developed, has little to no primary porosity and is unconfined. Hence, it is unlikely to exhibit barometric responses such as seen in confined systems (Merritt, 2004), whereby pore pressure changes due to barometric loading are substantially lower than the change of cave air pressure.

\subsubsection{Earth tides}

Earth tides are solid deformations of the Earth's surface caused by the gravitational pull of the moon and sun (Merritt, 2004). It has been previously shown that earth tides can cause regular oscillations in groundwater level if the aquifer is sufficiently confined (Acworth et al., 2015). However, at Glory Hole Cave this process can be ruled out due to the unconfined conditions and the fact that the compressibility of limestone is smaller than that of water and because fluctuations in pressure caused by earth tides are so small.

\subsubsection{Temperature-driven viscosity influences on hydraulic conductivity}

The study site has large surface temperature variations, particularly in summer where daytime and nighttime temperatures can vary up to $31.1^{\circ} \mathrm{C}$. Consequently, the dynamic viscosity of water could range from 0.8 to $1.79 \times 10^{-3} \mathrm{Pas}$ (based on a temperature range from 30 to $0^{\circ} \mathrm{C}$, respectively). However, the conductive propagation in diel temperature variations are expected to be highly attenuated with depth (Rau et al., 2015), resulting in almost complete damping by $1 \mathrm{mb}$ b.l. Furthermore, the daily temperature range within the cave itself is just $0.08-1.53{ }^{\circ} \mathrm{C}$, primarily due to air exchange moderated by conductive equilibrium with the cave walls. The variation of water viscosity (which is inversely proportional to hydraulic conductivity) is approximately 2 to $3 \%$ per degree in the range of 10 to $30^{\circ} \mathrm{C}$. Considering that the amplitude of a $1 \mathrm{cpd}$ drip rate fluctuation can be as much as $75 \%$ of the maximum drip rate, the greatest anticipated change in hydraulic conductivity, and therefore the drip rate (proportional to the hydraulic conductivity by Darcy's law), 
on a daily cycle is likely to be 2-3 orders of magnitude lower than the observed variation in drip rate on a daily basis. We therefore conclude that the daily fluctuations in drip rate are unlikely to be caused by variations in hydraulic conductivity due to changes in viscosity of water.

\subsubsection{Solar-driven daily cycles of (phreatophytic) evapotranspiration}

The timing of the daily drip rate signal appears to be associated with the difference in maximum and minimum surface temperature. In the examples examined in more depth in Fig. 4a and b, when the difference between the maximum and minimum temperature was high (17$22^{\circ} \mathrm{C}$ ) and the evapotranspiration was relatively high (mean $3.6 \mathrm{~mm} \mathrm{day}^{-1}$ ) the $1 \mathrm{cpd}$ signal was continuous. Conversely, when the temperature difference was small $\left(4.5-12.7^{\circ} \mathrm{C}\right)$ and the potential evapotranspiration was relatively lower (mean $2.2 \mathrm{~mm} \mathrm{day}^{-1}$ ), the $1 \mathrm{cpd}$ signal dissolved into chaos.

During periods when there are $1 \mathrm{cpd}$ oscillations in drip rate, there was a relationship between drip rate and surface temperature on a weekly timescale. The best example is in Fig. 6, where $\tau=-0.21$ (significant at $95 \%$ ) for a 2-day average air temperature and drip rate at G1 from 1 to 19 February 2014. We have demonstrated above that it cannot be air temperature driving the signal through either atmospheric tides or water viscosity changes. However, the relationship between surface temperature variability and $1 \mathrm{cpd}$ drip rate oscillations could be explained if the association with diurnal temperature variability is due to variations in solar radiation received at the surface, as solar radiation and air temperature influence transpiration (among other factors). We hypothesise that, firstly, tree water use was driving the intermittent daily oscillations in drip discharge demonstrated by the relationship between daily to weekly variations in surface air temperature and drip discharge and, secondly, the sporadic nature of the oscillations was driven by complexities in the karst architecture. It has been widely accepted that tree water use causes fluctuations of the water table (Gribovszki et al., 2010; Acworth et al., 2015). However, this is the first study that demonstrates diurnal fluctuation in cave drip rates most likely driven by tree water use.

The area above the cave and in the small uphill catchment is dominated by E. pauciflora and E. stelullata (Fig. 1). Eucalypt species have a bimodal root system with shallow lateral roots and vertically descending roots which penetrate into the profile to depths of up to $18 \mathrm{~m}$, with depth depending on soil characteristics and the degree to which the bedrock is fractured and conduits developed (Crombie, 1992; Farrington et al., 1996). Hence, these trees have the mechanism to abstract water from karst stores at depth, which supports our theory that tree water use causes daily oscillations in cave drip rate.

Tree water use from deep roots occurs when the upper layers are too dry and have a lower water potential than the soil water at deeper levels (Dawson and Pate, 1996; Zapater et

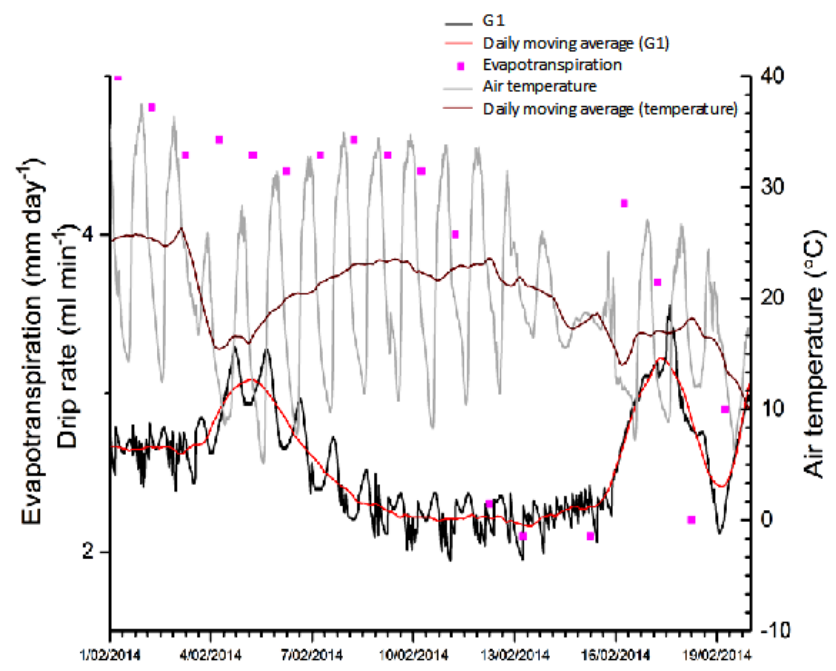

Figure 6. Surface air temperature, evapotranspiration and drip discharge rate with the corresponding daily moving average for site G1 1-19 February 2014.

al., 2011). Maximum tree water use by the roots is therefore expected in the afternoon during the period of maximum solar radiation, possibly lagged due to the time taken to hydraulically lift the water. Conversely, minimum tree water use is expected at the end of night around 06:00 LT. Burgess et al. (2001) measured sap flow in Eucalypt tap roots, finding tap root sap flow peaked around $1 \mathrm{pm}$ and negative sap flow values indicated reverse (acropetal) flow between 19:00 and 07:00 LT. In consideration of this, drip water that comes from fractures and stores which contain tree roots would be expected to have a minimum drip discharge in the afternoon and maximum around sunrise. In reality, we observe more complex daily drip oscillations, with peak drip rate occurring at different times of the day and different times of the year. This is to be expected from a karstified system with flow routed through a varied and complex fractured network. Different scenarios for daily oscillations in a karst system will be discussed in detail below.

\section{Scenarios for solar-driven daily cycles of phreatophytic evapotranspiration}

The depth of a store could affect the timing of daily drip rate oscillations due to the delay in tree water transport. For example, consider the hypothetical, identical trees with roots intercepting identical karst stores or fractures at different depths in Fig. 7a and b. There is likely to be a greater lag in drip response in Fig. 7a than Fig. 7b because of the longer flow path length $(F)$ from the tree root to the cave drip site. Given that eucalypt tap roots can penetrate to depths ranging from 5 to $20 \mathrm{~m}$ with tap root length depending on the depth of accessible water (Carbon et al., 1980; Dawson and Pate, 1996) and the drip sites at Glory Hole Cave are located 30 $50 \mathrm{~m}$ below the surface, we can speculate that the minimum 

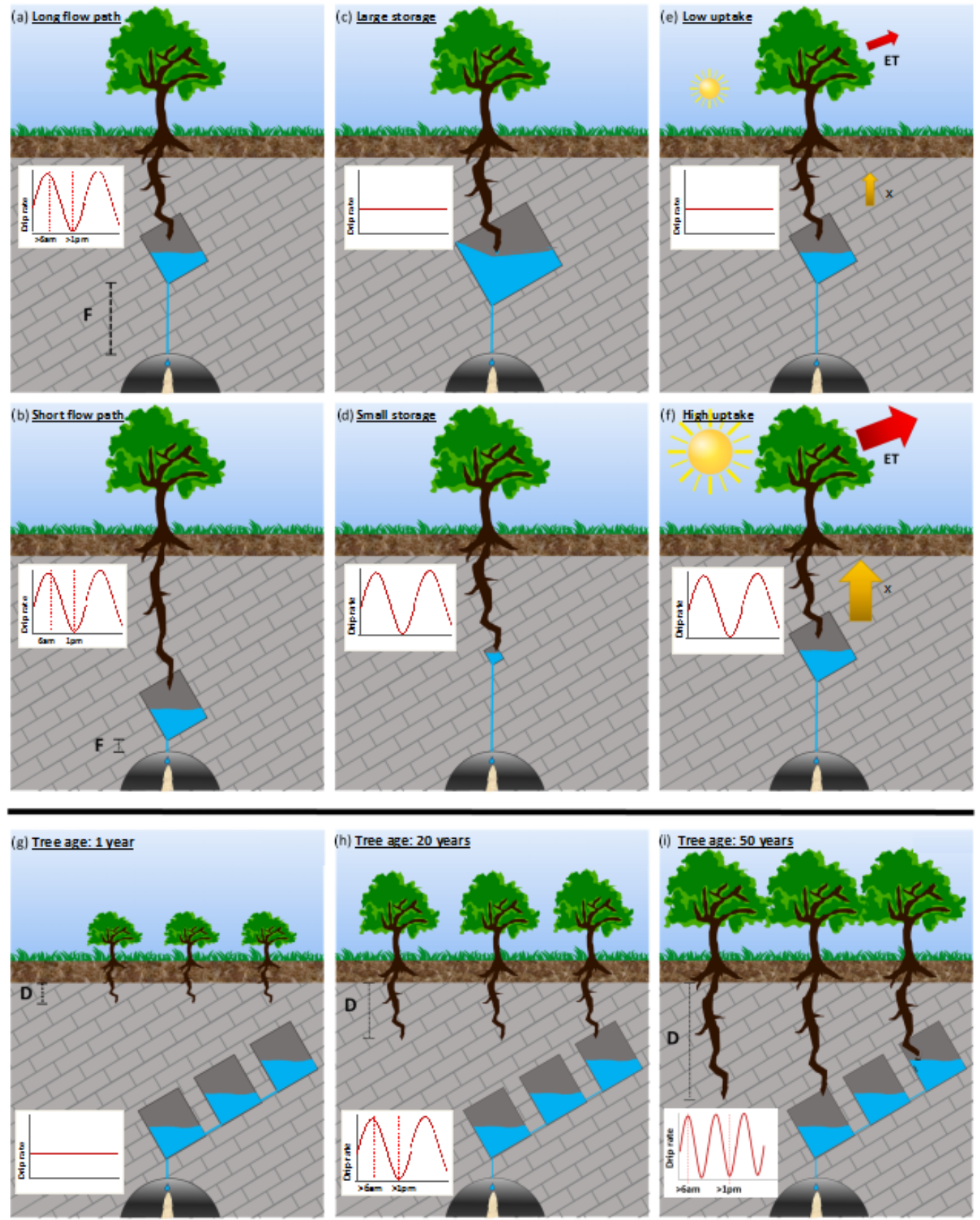

Figure 7. A conceptual representation of tree water use from karst stores under different circumstances. (a) and (b) show different karst store-drip site flow path lengths $(F)$ as the tree roots access karst stores at different depths; (c) and (d) show tree roots accessing karst stores with different volumes; the influence of annual insolation on evapotranspiration (ET) and root water uptake $(x)$ during winter and summer is shown in (e) and (f), respectively. Finally, the increase in rooting depth $(D)$ and access to deeper karst stores over time in years is explored in $(\mathbf{g})-(\mathbf{i})$.

flow path length between a taproot accessing the karst store and the drip site below could vary from 10 to $45 \mathrm{~m}$. In reality, it is difficult to calculate exact flow path length because of the prevalence of lateral flow in heavily karstified systems. This has been demonstrated by Markowska et al. (2016) in a study where water spiked with a tracer was used to irrigate the surface above a cave, resulting in a response at discharge sites located $7 \mathrm{~m}$ laterally from the irrigation location. Across all sites, lag time between maximum air temperature and minimum drip rate ranged from 0.25 to $24 \mathrm{~h}$ (Table 2). We can 
hypothesise that those sites with a shorter lag time have a shorter path length from tree root accessed store to cave discharge site than the other drip sites. For example, the lag time for site $\mathrm{G} 1$ ranges from 11.25 to $12.75 \mathrm{~h}$ whereas site $\mathrm{G} 10$ ranges from 0.5 to $3 \mathrm{~h}$. This process could also explain the large variation in lag time within a particular site, for example at G6 the lag time was $21 \mathrm{~h}$ in May 2014 and decreased to $7 \mathrm{~h}$ in August 2014 (Table 2). We hypothesise that the change could be due to a shortening of the path length from root accessed store to cave discharge site as the tree grows and increases its rooting depth, thus accessing a deeper water store. Alternatively, this could also be the result of compensation as a shallow water store dries up and a deeper section of the root network is utilised.

The size of the karst store, or volume of water within the store, could determine whether the daily oscillation is observable or not. Consider the conceptual Fig. 7c and d, where identical trees have roots intercepting different karst stores at the same depth. We propose that a daily oscillation will only be observed when the tree water use is a significant part of the total water store so a daily oscillation is more likely to be observed in the smaller store (Fig. 7d) than a store with a larger volume (Fig. 7c). The influence of store volume on the presence of daily oscillations could also explain why the phenomenon is not observed at M1. In Sect. 3.1 we discuss how the low, consistent drip rate at M1 responds to seasonal drying but does not respond to individual rainfall events. We propose that this site is fed by a store large enough to assimilate individual rainfall events and the same line of reasoning could explain the lack of response to tree water use, the volume of water extracted by tree roots is insignificant in relation to the large volume of water in the store. Conversely, we can hypothesise that G6 has a small store volume that is more sensitive to water uptake by tree roots, which is why we see the minimum drip rate occurring $0.25-7 \mathrm{~h}$ before peak air temperature (Table 2). Furthermore, this scenario is supported by the fact that, generally, the daily oscillations are not exhibited during periods of high rainfall, and consequently high drip discharge, as the tree use signal is more likely to be a smaller fraction of the total water volume. Sites G1, G3 M2 and M4 have high seasonal discharge rates during June-September as indicated by the multiple hydrograph peaks for the corresponding sites in Fig. 3. There are no daily oscillations during these periods of peak discharge at any of these sites. Daily oscillations coincide with the receding limb of the peak at sites M4 (July and September 2013) and M4 (September 2013) as the drip rate decreases. The non-observance of daily oscillations during periods of high rainfall could also be attributed to the redistribution of water by the roots from the saturated soil to the unsaturated subsurface (Burgess et al., 2001).

Tree water use responds to annual variation in insolation. Consider Fig. 7e and f, where one tree root intercepts the same karst store over the course of a year. During winter (Fig. 7e), there is less insolation than the summer (Fig. 7f); therefore the rate of evapotranspiration is lower. This means that in winter the hydraulic lift is low or negative and daily oscillations in drip discharge could be dampened or absent. Our analysis reveals that only 2 out of 41 periods of $1 \mathrm{cpd}$ oscillation occur during winter months June-August (G6 between 14 and 24 August 2013 and M2 between 8 and 13 July 2013). However, our analysis also revealed that season did not explain a significant amount of variance in lag time, thus suggesting that more variables, such as karst architecture, are affecting the timing of drip rate oscillations.

In reality, there are multiple trees of different ages above the cave, further complicating the flow variability. Figure $7 \mathrm{~g}-$ i present a conceptual representation of tree tap root length increasing $(D)$ as the tree grows and accesses deeper karst stores over 1-50-year timescale. This response to annual insolation and the interaction of multiple trees of varying ages could explain why daily oscillations at an individual drip site occur one year and not the next; for example at M10 there is a $1 \mathrm{cpd}$ in December 2012, but this oscillation does not occur at the same time in 2013 or 2014. The mechanism in Fig. 7i could also explain why $2 \mathrm{cpd}$ signals are also observed, whereby multiple tree roots access interconnected water stores at different depths, resulting in two separate cycles with differing lag times. The occurrence of 2 cpd signals in drip rate could also be related to signal processing where if the signal is not strictly sinusoidal there may be harmonics in the spectrum. This finding and the interpretation is an area for further research.

\subsection{Implications for karst architecture and climate proxy modelling research}

Karst architecture controls flow regimes and drip discharge rates of water infiltrating into caves (e.g. Markowska et al., 2015). Flow rate influences speleothem climate proxies, such as the $\delta^{18} \mathrm{O}$ and concentration of solutes in drip water, through the dilution and mixing of percolation waters prior to reaching the cave. It is important to distinguish between the influence of karst architecture and climate-driven processes, such as drought, on discharge so that paleoclimate proxy records from associated speleothems can be appropriately constrained. This study has increased our understanding of karst architecture, information which can be utilised in proxy-system models or forward models, approaches that are increasingly used to understand cave drip rate variability and to model speleothem proxies such as $\delta^{18} \mathrm{O}$ (Bradley et al., 2010; Cuthbert et al., 2014a). Additionally, we propose that an important part of any protocol for inferring karst architecture is (1) the incorporation of cave drip rate monitoring with a minimum $15 \mathrm{~min}$ interval at multiple discharge sites for at least a year and (2) the systematic investigation of daily, weekly and monthly timescales using frequency analysis capable of showing frequency-time changes, such as the synchrosqueeze transform (Daubechies et al., 2011), to infer karst flow processes and their relative importance. This 
study clearly demonstrates the potential for vegetation to impact karst water recharge, making this research relevant to karst modelling and karst water resources assessment. Currently, there are no approaches that consider the impacts of vegetation on recharge dynamics in process-based karst models (Hartmann et al., 2014b, 2015) or in empirical recharge estimation approaches (Allocca et al., 2014; Andreo et al., 2006).

This is the first indirect volumetric observation of tree water use in cave drip water. This supports a growing number of studies examining the impact of trees on karst processes and paleoclimate proxies. For example, tree root respiration provides a source of $\mathrm{CO}_{2}$ for the dissolution of limestone that is additional to that from soil and vadose zone microbial respiration. Coleborn et al. (2016) found that vegetation regeneration determined post-fire soil $\mathrm{CO}_{2}$ in a study investigating post-fire impacts on karst processes. Direct observations of tree water use within the karst unsaturated zone implies the presence of root respiration, a process which in turn affects drip water and speleothem ${ }^{14} \mathrm{C}$ and $\delta{ }^{13} \mathrm{C}$ composition (Fairchild and Baker, 2012; Meyer et al., 2014; Noronha et al., 2015). Trees have been demonstrated to have long-term effects on cave drip water solute concentrations. Treble et al. (2015) demonstrate long-term trends in drip water calcium and trace element concentration, which they attribute to increasing solute concentration due to forest regrowth and increased post-fire tree water use. Baldini et al. (2005) infer an effect on speleothem $\delta^{18} \mathrm{O}$ due to secondary forest regrowth after mining and Wong and Banner (2010) found clearing surface vegetation changed drip water $\mathrm{Mg} / \mathrm{Ca}$ and $\mathrm{Sr} / \mathrm{Ca}$. The findings and suggested protocol in this study will inform the selection of speleothem specimens for further research into the impact of tree water use on speleothem paleoclimate proxies.

\section{Conclusions}

We demonstrated a novel method of analysing recurring patterns in cave water drip rate using the WSST. Our analysis revealed daily and sub-daily oscillations with variable temporal and spatial signatures. We tested competing hypotheses for causes of daily oscillations using drip rate, barometric and temperature data. The only hypothesis which all the data and hydrologic theory were consistent with was that daily fluctuations in drip rate were driven by tree water use. We proposed that the complexity of flow pathways in the karst system accounted for the spatial and temporal variation in the daily fluctuations of drip rates. This was explored in detail using conceptual models. The results have wider implications for karst research, including providing a new protocol for inferring karst architecture, informing selection of speleothem specimens for tree water use paleoclimate studies and highlighting the importance of vegetation dynamics on karst recharge.

\section{Data availability}

Data are available on figshare under doi:10.6084/m9.figshare.4056345.

\section{The Supplement related to this article is available online at doi:10.5194/hess-20-4439-2016-supplement.}

Author contributions. Katie Coleborn, Mark O. Cuthbert, Gabriel C. Rau and Andy Baker wrote the manuscript, discussed the results and implications and commented on the manuscript at all stages. Katie Coleborn, Andy Baker and Owen Navarre collected data. Gabriel C. Rau performed the WSST analysis and generated the WSST and CWT figures. Gabriel C. Rau and Owen Navarre created the location map. Katie Coleborn and Gabriel C. Rau generated other graphs and conceptual figures.

Acknowledgements. We acknowledge that Katie Coleborn was supported the Australian Research Council (LP130100177). Mark Cuthbert was supported by Marie Curie Research Fellowship funding from the European Community's Seventh Framework Programme (FP7/2007-2013) under grant agreement no. 299091. We would also like to thank Stuart Hankin for allowing us access to the weather station data and the National Parks and Wildlife Service staff at Yarrangobilly Caves. Solar exposure data derived from satellite imagery processed by the Bureau of Meteorology from the Geostationary Meteorological Satellite and MTSAT series operated by Japan Meteorological Agency and from GOES-9 operated by the National Oceanographic \& Atmospheric Administration (NOAA) for the Japan Meteorological Agency. We would also like to acknowledge the use of equipment funded by the Australian Government National Collaborative Research Infrastructure Strategy (NCRIS).

Edited by: T. Blume

Reviewed by: two anonymous referees

\section{References}

Acworth, R. I., Rau, G. C., McCallum, A. M., Andersen, M. S., and Cuthbert, M. O.: Understanding connected surfacewater/groundwater systems using Fourier analysis of daily and sub-daily head fluctuations, Hydrogeol. J., 23, 143-159, doi:10.1007/s10040-014-1182-5, 2015.

Adamson, L. and Loudon, A.: Wagga Geological Sheet, $1: 250000$, SI/55-15, 1st Edn., Geological Survey of New South Wales, Sydney, 1966.

Allocca, V., Manna, F., and De Vita, P.: Estimating annual groundwater recharge coefficient for karst aquifers of the southern Apennines (Italy), Hydrol. Earth Syst. Sci., 18, 803-817, doi:10.5194/hess-18-803-2014, 2014.

Andreo, B., Vias, J., Duran, J. J., and Jimenez, P.: Methodology for groundwater recharge assessment in carbonate aquifers: application to pilot sites in southern Spain, Hydrogeol. J., 16, 911-925, 2006. 
Arbel, Y., Greenbaum, N., Lange, J., and Inbar, M.: Infiltration processes and flow rates in developed karst vadose zone using tracers in cave drips, Earth Surf. Proc. Land., 35, 1682-1693, doi:10.1002/esp.2010, 2010.

Auger, F. and Flandrin, P.: Improving the readability of timefrequency and time-scale representations by the reassignment method, IEEE Trans. Signal Process., 43, 1068-1089, doi:10.1109/78.382394, 1995.

Baker, A. and Brunsdon, C.: Non-linearities in drip water hydrology: an example from Stump Cross Caverns, Yorkshire, J. Hydrol., 277, 151-163, doi:10.1016/S0022-1694(03)00063-5, 2003.

Baker, A., Bradley, C., Phipps, S. J., Fischer, M., Fairchild, I. J., Fuller, L., Spötl, C., and Azcurra, C.: Millennial-length forward models and pseudoproxies of stalagmite $\delta^{18} \mathrm{O}$ : an example from NW Scotland, Clim. Past, 8, 1153-1167, doi:10.5194/cp-8-11532012, 2012.

Baldini, J. U. L., McDermott, F., Baker, a, Baldini, L. M., Mattey, D. P., and Railsback, L. B.: Biomass effects on stalagmite growth and isotope ratios: A 20th century analogue from Wiltshire, England, Earth Planet. Sc. Lett., 240, 486-494, doi:10.1016/j.eps1.2005.09.022, 2005.

Baldini, J. U. L., McDermott, F., Baldini, L. M., Ottley, C. J., Linge, K. L., Clipson, N., and Jarvis, K. E.: Identifying short-term and seasonal trends in cave drip water trace element concentrations based on a daily-scale automatically collected drip water dataset, Chem. Geol., 330-331, 1-16, doi:10.1016/j.chemgeo.2012.08.009, 2012.

Bradley, C., Baker, A., Jex, C. N., and Leng, M. J.: Hydrological uncertainties in the modelling of cave dripwater $\delta^{18} \mathrm{O}$ and the implications for stalagmite palaeoclimate reconstructions, Quaternary Sci. Rev., 29, 2201-2214, doi:10.1016/j.quascirev.2010.05.017, 2010.

Bradley, C., Wood, A., Baker, A., Jex, C. N., Fairchild, I. J., Gagan, M. K., Cowley, J., and Azcurra, C.: An isotopic and modelling study of flow paths and storage in Quaternary calcarenite, SW Australia: implications for speleothem paleoclimate records, Quaternary Sci. Rev., 64, 90-103, doi:10.1016/j.quascirev.2012.12.015, 2013.

Burgess, S. S. O., Adams, M. A., Turner, N. C., White, D. A., and Ong, C. K.: Tree roots: Conduits for deep recharge of soil water, Oecologia, 126, 158-165, doi:10.1007/s004420000501, 2001.

Carbon, B. A., Bartle, G. A., Murray, A. M., and Macpherson, D. K.: The distribution of root length, and the limits to flow of soil water to roots in a dry sclerophyll forest, Forest Sci., 26, 656664,1980

Coleborn, K., Spate, A., Tozer, M., Andersen, M. S., Fairchild, I. J., Mackenzie, B., Treble, P. C., Meehan, S., Baker, A., and Baker, A.: Effects of wildfire on long-term soil $\mathrm{CO}_{2}$ concentration: implications for karst processes, Environ. Earth Sci., 75, 330, 2016.

Collister, C. and Mattey, D.: Controls on water drop volume at speleothem drip sites: An experimental study, J. Hydrol., 358, 259-267, doi:10.1016/j.jhydrol.2008.06.008, 2008.

Crombie, D. S.: Root depth, leaf area and daytime water relations of Jarrah (Eucalyptus marginata) forest overstorey and understorey during summer drought, Aust. J. Bot., 40, 113-22, doi:10.1071/BT9920113, 1992.

Cuthbert, M., Baker, A., Jex, C., Graham, P., Treble, P., Andersen, M., and Acworth, I.: Drip water isotopes in semi-arid karst:
Implications for speleothem paleoclimatology, Earth Planet. Sc. Lett., 395, 194-204, doi:10.1016/j.eps1.2014.03.034, 2014a.

Cuthbert, M. O., Rau, G. C., Andersen, M. S., Roshan, H., Rutlidge, H., Marjo, C. E., Markowska, M., Jex, C. N., Graham, P. W., Mariethoz, G., Acworth, R. I., and Baker, A.: Evaporative cooling of speleothem drip water, Sci. Rep., 4, 5162, doi:10.1038/srep05162, 2014b.

Daubechies, I., Lu, J., and Wu, H. T.: Synchrosqueezed wavelet transforms: An empirical mode decompositionlike tool, Appl. Comput. Harmon. Anal., 30, 243-261, doi:10.1016/j.acha.2010.08.002, 2011

Dawson, T. E. and Pate, J. S.: Seasonal water uptake and movement in root systems of Australian phraeatophytic plants of dimorphic root morphology: a stable isotope investigation, Oecologia, 107, 13-20, doi:10.1007/BF00582230, 1996.

Fairchild, I. J. and Baker, A.: Speleothem Science: From Process to Past Environments, 1st End., Wiley-Blackwell, Chichester, UK, 2012.

Fairchild, I. J., Borsato, A., Tooth, A. F., Frisia, S., Hawkesworth, C. J., Huang, Y., and Mcdermott, F.: Controls on trace element žSr-Mg/compositions of carbonate cave waters: implications for speleothem climatic records, Chem. Geol., 166, 255269, doi:10.1016/S0009-2541(99)00216-8, 2000.

Farrington, P., Turner, J., and Gailitis, V.: Eucalyptus marginata, Trees, 11, 9-15, 1996.

Ford, D. and Williams, P. D.: Karst Hydrogeology and Geomorphology, Wiley, Chichester, 1994.

Genty, D. and Deflandre, G.: Drip flow variations under a stalactite of the Pere Noel cave (Belgium). Evidence of seasonal variations and air pressure constraints, J. Hydrol., 211, 208-232, doi:10.1016/S0022-1694(98)00235-2, 1998.

Gribovszki, Z., Szilágyi, J., and Kalicz, P.: Diurnal fluctuations in shallow groundwater levels and streamflow rates and their interpretation - A review, J. Hydrol., 385, 371-383, doi:10.1016/j.jhydrol.2010.02.001, 2010.

Hartmann, A., Goldscheider, N., Wagener, T., Lange, J., and Weiler, M.: Karst water resources in a changing world: Approaches, of hydrological modeling, Rev. Geophys., 1, 1-25, doi:10.1002/2013RG000443, 2014a.

Hartmann, A., Mudarra, M., Andreo, B., Marin, A., Wagener, T., and Lange, J.: Modelling spatiotemporal impacts of hydroclimatic extremeson groundwater recharge at a Mediterranean karst aquifer, Water Resour. Res., 50, 6507-6521, doi:10.1002/2014WR015685, 2014b.

Hartmann, A., Gleeson, T., Rosolem, R., Pianosi, F., Wada, Y., and Wagener, T.: A large-scale simulation model to assess karstic groundwater recharge over Europe and the Mediterranean, Geosci. Model Dev., 8, 1729-1746, doi:10.5194/gmd-81729-2015, 2015.

Hu, C., Henderson, G. M., Huang, J., Chen, Z., and Johnson, K. R.: Report of a three-year monitoring programme at Heshang Cave, Central China, Int. J. Speleol., 37, 143-151, doi:10.5038/1827806X.37.3.1, 2008.

Jex, C. N., Mariethoz, G., Baker, A., Graham, P., Andersen, M. S., Acworth, I., Edwards, N., and Azcurra, C.: Spatially dense drip hydrological monitoring and infiltration behaviour at the Wellington Caves, South East Australia, Int. J. Speleol., 41, 283 296, 2012. 
Lange, J., Arbel, Y., Grodek, T., and Greenbaum, N.: Water percolation process studies in a Mediterranean karst area, Hydrol. Process., 24, 1866-1879, doi:10.1002/hyp.7624, 2010.

Mahmud, K., Mariethoz, G., Baker, A., Treble, P. C., Markowska, M., and McGuire, E.: Estimation of deep infiltration in unsaturated limestone environments using cave lidar and drip count data, Hydrol. Earth Syst. Sci., 20, 359-373, doi:10.5194/hess20-359-2016, 2016.

Mariethoz, G., Baker, A., Sivakumar, B., Hartland, A., and Graham, P.: Chaos and irregularity in karst percolation, Geophys. Res. Lett., 39, L23305, doi:10.1029/2012GL054270, 2012.

Markowska, M., Baker, A., Treble, P. C., Andersen, M. S., Hankin, S., Jex, C. N., Tadros, C. V., and Roach, R.: Unsaturated zone hydrology and cave drip discharge water response: Implications for speleothem paleoclimate record variability, J. Hydrol., 529, 662-675, doi:10.1016/j.jhydrol.2014.12.044, 2015.

McDonald, J.: The 2002-2003 El Niño recorded in Australian cave drip waters: Implications for reconstructing rainfall histories using stalagmites, Geophys. Res. Lett., 31, L22202, doi:10.1029/2004GL020859, 2004.

McDonald, J. and Drysdale, R.: Hydrology of cave drip waters at varying bedrock depths from a karst system in southeastern Australia, Hydrol. Process., 21, 1737-1748, doi:10.1002/hyp.6356, 2007.

Merritt, M. L.: Estimating Hydraulic Properties of the Floridan Aquifer System by Analysis of Earth-Tide, Ocean-Tide, and Barometric Effects, Collier and Hendry Counties, Florida, United States Geological Survey Publication, USA, 2003-4267, 2004.

Meyer, K. W., Feng, W., Breecker, D. O., Banner, J. L., and Guilfoyle, A.: Interpretation of speleothem calcite $\delta^{13} \mathrm{C}$ variations: Evidence from monitoring soil $\mathrm{CO}_{2}$, drip water, and modern speleothem calcite in central Texas, Geochim. Cosmochim. Acta, 142, 281-298, doi:10.1016/j.gca.2014.07.027, 2014.

Noronha, A. L., Johnson, K. R., Southon, J. R., Hu, C., Ruan, J., and McCabe-Glynn, S.: Radiocarbon evidence for decomposition of aged organic matter in the vadose zone as the main source of speleothem carbon, Quaternary Sci. Rev., 127, 37-47, doi:10.1016/j.quascirev.2015.05.021, 2015.

Peel, M. C., Finlayson, B. L., and McMahon, T. A.: Updated world map of the Köppen-Geiger climate classification, Hydrol. Earth Syst. Sci., 11, 1633-1644, doi:10.5194/hess-11-16332007, 2007.

Proctor, C. J., Baker, A., Barnes, W. L., and Gilmour, M. A.: A thousand year speleothem proxy record of North Atlantic climate from Scotland, Clim. Dynam., 16, 815-820, doi:10.1007/s003820000077, 2000.

Rau, G. C., Cuthbert, M. O., Andersen, M. S., Baker, A., Rutlidge, H., Markowska, M., Roshan, H., Marjo, C. E., Graham, P. W., and Acworth, R. I.: Controls on cave drip water temperature and implications for speleothem-based paleoclimate reconstructions, Quaternary Sci. Rev., 127, 1-18, doi:10.1016/j.quascirev.2015.03.026, 2015.

Rutlidge, H., Baker, A., Marjo, C. E., Andersen, M. S., Graham, P. W., Cuthbert, M. O., Rau, G. C., Roshan, H., Markowska, M., Mariethoz, G., and Jex, C. N.: Dripwater organic matter and trace element geochemistry in a semi-arid karst environment: Implications for speleothem paleoclimatology, Geochim. Cosmochim. Ac., 135, 217-230, doi:10.1016/j.gca.2014.03.036, 2014.
Scott, T. M., Campbell, K. M., Rupert, F. R., Arthur, J. D., Missimer, T. M., Lloyd, J. M., Yon, J. W., and Duncan, J. G., Geologic Map of the State of Florida, Map Series 146, Florida Geological Survey and Florida Department of Environmental Protection, USA, 2001.

Sheffer, N. A., Cohen, M., Morin, E., Grodek, T., Gimburg, A., Magal, E., Gvirtzman, H., Nied, M., Isele, D., and Frumkin, A.: Integrated cave drip monitoring for epikarst recharge estimation in a dry Mediterranean area, Sif Cave, Israel, Hydrol. Process., 25, 2837-2845, doi:10.1002/hyp.8046, 2011.

Sondag, F., Van Ruymbeke, M., Soubiès, F., Santos, R., Somerhausen, A., Seidel, A., and Boggiani, P.: Monitoring present day climatic conditions in tropical caves using an Environmental Data Acquisition System (EDAS), J. Hydrol., 273, 103-118, doi:10.1016/S0022-1694(02)00362-1, 2003.

Spate: Karst Values, New South Wales Office of Environment and Heritage, Hurstville, Australia, 33-46, 2002.

Stern, H., de Hoedt, G., and Ernst, J.: Objective classification of Australian Climates, Bur. Meteorol., available at: http://www.bom.gov.au/climate/environ/other/koppen_ explain.shtml (last access: 15 October 2013), 2012.

Thakur, G., Brevdo, E., Fučkar, N. S., and Wu, H. T.: The Synchrosqueezing algorithm for time-varying spectral analysis: Robustness properties and new paleoclimate applications, Signal Process., 93, 1079-1094, doi:10.1016/j.sigpro.2012.11.029, 2013.

Tooth, A. F. and Fairchild, I. J.: Soil and karst aquifer hydrological controls on the geochemical evolution of speleothem-forming drip waters, Crag Cave, southwest Ireland, J. Hydrol., 273, 5168, doi:10.1016/S0022-1694(02)00349-9, 2003.

Torrence, C. and Compo, G. P.: A Practical Guide to Wavelet Analysis, B. Am. Meteorol. Soc., 79, 61-78, doi:10.1175/15200477(1998)079<0061:APGTWA>2.0.CO;2, 1998.

Treble, P. C., Fairchild, I. J., Griffiths, A., Baker, A., Meredith, K. T., Wood, A., and McGuire, E.: Impacts of cave air ventilation and in-cave prior calcite precipitation on Golgotha Cave dripwater chemistry, southwest Australia, Quaternary Sci. Rev., 127, 6172, doi:10.1016/j.quascirev.2015.06.001, 2015.

Treble, P. C., Fairchild, I. J., Baker, A., Meredith, K. M., Andersen, M. S., Salmon, S. U., Bradley, C., Wynn, P. M., Hankin, S., Wood, A., and McGuire, E.: Roles of forest bioproductivity, transpiration and fire in a nine-year record of cave dripwater chemistry from southwest Australia, Geochim. Cosmochim. Ac., 184, 132-150, 2016.

Treble, P. C., Markowska, M., Tadros, C., Jex, C., Coleborn, K., Dredge, J., Baker, A., Roach, R., and Spate, A.: Reconstructing past environmental change at Yarrangobilly Caves, in: Caves and karst of Yarrangobilly, edited by: Ellis, R. and Halbert, E., Sydney Speleological Society Occasional Paper No. 19, Sydney Speleological Society, Sydney, 95-100, 2016 b.

Tremaine, D. M. and Froelich, P. N.: Speleothem trace element signatures: A hydrologic geochemical study of modern cave dripwaters and farmed calcite, Geochim. Cosmochim. Ac., 121, 522545, doi:10.1016/j.gca.2013.07.026, 2013.

Webb, M., Dredge, J., Barker, P. A., Müller, W., Jex, C., Desmarchelier, J., Hellstrom, J., and Wynn, P. M.: Quaternary climatic instability in south-east Australia from a multi-proxy speleothem record, J. Quatern. Sci., 29, 589-596, doi:10.1002/jqs.2734, 2014. 
Wong, C. and Banner, J. L.: Response of cave air $\mathrm{CO}_{2}$ and drip water to brush clearing in central Texas: Implications for recharge and soil $\mathrm{CO}_{2}$ dynamics, J. Geophys. Res., 115, G04018, doi:10.1029/2010JG001301, 2010.

Worboys, G.: Koscuisko National Park Geology and Geomorphology, National Parks and Wildlife Services, Sydney, 1982.
Zapater, M., Hossann, C., Bréda, N., Bréchet, C., Bonal, D., and Granier, A.: Evidence of hydraulic lift in a young beech and oak mixed forest using ${ }^{18} \mathrm{O}$ soil water labelling, Trees Struct. Funct., 25, 885-894, doi:10.1007/s00468-011-0563-9, 2011. 